\title{
Fear of hypoglycemia in Italian mothers of children with type 1 diabetes: the mediating role of resilience
}

\author{
Paola Cardinali ${ }^{1}$, Elisa Rapetti ${ }^{1}$, Laura Migliorini ${ }^{1}$ \\ 1 Department of Education Science, University of Genoa \\ Keywords: mediation model., parental role, resilience, fear of hypoglycemia, diabetes \\ https://doi.org/10.52965/001c.27439
}

Health Psychology Research

Vol. 9, Issue 1, 2021

\begin{abstract}
Objective
Fear of hypoglycemia for children with diabetes influences parental life and could increase parental stress. The present study aimed to explore the association between resilience, the self-perception of the parental role, and fear of hypoglycemia in mothers of children with type I diabetes (T1DM).
\end{abstract}

\section{Methods}

Ninety mothers (mean age: 44.20 years) of children with a T1DM diagnosis (mean age: 11.48 years) were recruited from an association for parents and completed an online self-report questionnaire packet that includes: Fear of Hypoglycemia Survey, Self-Perception of the Parental Role and Resilience Scale for Adults. Participants were recruited in 2017. Data collection lasted 10 months. Data analysis was performed using the SPSS statistical package, version 22, and the PROCESS macro program by Hayes.

\section{Results}

The analysis of the mediation model shows that resilience assumes a mediational role in the relationships between the parental role and preoccupation with hypoglycemia. In particular, the mother's perceived competence and role balance can influence the development and increase of the mother's resilience, which in turn can allow a decrease in the mother's worry about the possible hypoglycemic episode of her child.

\section{Conclusion}

The findings suggest that resilience is a significant topic to focus on in interventions designed to increase the self-perception of the parental role and reduce fear of hypoglycemia in mothers

\section{INTRODUCTION}

Type 1 diabetes mellitus (T1DM) is a chronic endocrine disorder that usually develops in childhood and adolescence. Its incidence is increasing rapidly in Italy and other countries. ${ }^{1-3}$ Recent epidemiological data indicate that approximately 20.000 children and adolescents have been diagnosed with T1DM in Italy. ${ }^{4}$ T1DM has a significant effect on both young patients and their parents. It is necessary to face several changes in the daily family lifestyle. ${ }^{5,6}$ The literature supports the importance of familial characteristics in children with type 1 diabetes. ${ }^{7}$ Parental involvement is essential for adherence in managing a chronic pediatric illness, for responsibility for diabetes tasks, and supporting children in becoming autonomous. ${ }^{8}$ Parents must quickly become experts in diabetes care and the insulin treatment of their children. ${ }^{2,9,10}$

Parents may have difficulties managing daily life, such as checking blood glucose levels, carbohydrate counting, and determining and administering insulin doses. ${ }^{3}$ They may experience psychological difficulties, ranging from anxiety and preoccupation to the possible development of some disorders (including a greater prevalence of posttraumatic stress disorder and depression). ${ }^{11,12}$ Furthermore, such a diagnosis is a burden, and the stress level is more significant in the parents of school-age children. ${ }^{13}$

Guidelines to managing T1DM advise maintaining the lowest level of hemoglobin (HbA1c). This can be achieved without severe hypoglycemia, hyperglycemia, or diabetes ketoacidosis. $^{2,14}$

Hypoglycemia is one of the most frequent preoccupations of parents of children with diabetes. ${ }^{15,16}$ It is a common acute complication in insulin-treated diabetes; perhaps it is so feared by parents because, due to the low glucose level in the blood, hypoglycemia can lead to illness or even coma and death. ${ }^{17}$ Hypoglycemia affects children's daily routines (school performance, sibling and peer relationships, and activities) and families' daily routines. ${ }^{2,18-20}$ Being aware of parents' fear of hypoglycemia is essential because it may influence parent stress ${ }^{21}$ and treatment 
management. ${ }^{3}$ The diagnosis of chronic disease in a child or adolescent and the related new concerns lead to changes in parents' beliefs and perceptions, even towards their idea of the parental role. ${ }^{5,22}$ Parents desire to allow their child to live peacefully, without limitations, and without being made to feel different. ${ }^{23}$ Parents can experience negative feelings that can affect their perception of the parental role. This perception plays a vital role in parent-child interactions because it can influence the behavior and management of caregiving. ${ }^{24}$ This self-perception is a critical component of parents' behavior because parents who have a positive perception of their role have been found to feel closer to their children. ${ }^{25}$ This perception includes mutually influenced elements, such as gratification, investment in caregiving, and the ability to balance one's roles. During the life span, role balance can generally be defined as the global appraisal of the harmony and the integration among one's different life roles and aims. Parents must establish individual and relational role identities to maximize their success and satisfaction across their life domains. ${ }^{26}$ The role of parents must be in balance with other social roles that characterize the individual during their life cycle, for example, as a partner, friend, and worker, to allow better management of stress in their daily life. However, parents of children with TD1M tend to be unbalanced regarding their caregiving role. ${ }^{24}$ These data are significant, especially for mothers who most frequently take on the role of caregiver. ${ }^{27}$ A study by Kobos and colleagues ${ }^{13}$ shows that the burden of providing care falls primarily on the mothers of children with T1DM and experience higher levels of worry than fathers. ${ }^{28}$

Furthermore, mothers are more involved in diabetes management than are fathers. ${ }^{2}$ Another study conducted in the Italian context about the caregiving role in chronic conditions shows that worries about the future are a significant theme for fathers. At the same time, mothers are more focused on the present. ${ }^{29}$

In particular, some studies show that mothers of children with diabetes use more psychological control than mothers of healthy children. A mother's psychological control is associated with the poorer wellbeing of the child, thus shaping long-lasting effects on the mother-child relationship. ${ }^{30}$

Overall, having a good perception of oneself is a condition that promotes behavior related to overcoming obstacles $^{22}$ and is linked to the development of resilience. ${ }^{31,32}$ At the same time, individuals who develop resilience are perceived as more able to cope with new situations. 33

Resilience is the ability of individuals to cope with and remove themselves from stressful and difficult situations, which is strengthened by adversity. ${ }^{34}$ Masten \& Obradovic 35 define resilience as a process of adaptation rather than an individual trait. Resilience represents a normal but not an absolute task of human functioning and can be modified with changing life circumstances. Some studies have already explored the role of resilience in patients affected by chronic illness. ${ }^{36-38}$ Specifically, Yi-Frazier and colleagues' ${ }^{10}$ study explores the association between resilience and distress, coping, and diabetes outcomes in adolescents with T1DM. The results show that higher resilience is associated with lower distress, higher quality of life, and improved diabetes outcomes. Some studies suggest a clinical approach focused on resilience for parents of children with chronic illness to decrease their levels of distress and ineffective behavior. ${ }^{39}$ Lee and colleagues ${ }^{40}$ define family resilience as being characterized by the ability to bounce in the process of coping when a member has a chronic illness. Attachment and cohesion among family members are two important elements of the family resilience response to distress. ${ }^{41}$

On the other hand, parents can also activate their resources and reorganize their role to cope with adverse psychological reactions, remove themselves from related situations and avoid long-term consequences. ${ }^{42}$ However, studies about parents' resilience in caring for a child with T1DM are rare. ${ }^{43}$

Researchers suggest meaningful relationships between several individual differences and resilience, but they also indicate that resilience is a significant predictor of psychosocial adjustment. ${ }^{44}$

Given the evidence of resilience as both an outcome and a predictor, it might mediate by influencing the relationship between individual characteristics, such as the self-perception of the parental role and parents' behaviors in certain contexts (e.g., fear of hypoglycemia).

This study was designed to explore the role of resilience in this relationship in parents of children with T1DM. In particular, we chose to focus on mothers, as the literature has identified them as the more involved caregiver both in management and psychological burden.

To fill the knowledge gaps, this study aimed to provide theoretical and practical implications by examining how resilience may play a mediating role in the relationship between the perceived parental role and fear of hypoglycemia in mothers of children with T1DM.

Therefore, two hypotheses were developed in this study:

H1: Mothers of children with a chronic disease might negatively perceive their parental role compared to a normative group.

$\mathrm{H} 2$ : Positive dimension of their parenting role might predict higher levels of resilience that could reduce the mothers' worry about the possible hypoglycemic status of their child.

\section{MATERIALS AND METHODS}

\section{PROCEDURE}

The study was presented to the parents during an assembly of a local association for parents of children with a T1DM diagnosis. After the public speaking presentation, parents were approached by a research assistant who asked them to volunteer to study various aspects of their family functioning related to the child's diabetes. After obtaining written informed consent from each participant, the questionnaire was sent to all the interested people by email. All the participants completed an online self-report questionnaire packet. Participants were recruited in 2017. Data collection lasted 10 months

\section{PARTICIPANTS}

Ninety mothers were recruited from an association for parents of children and adolescents with a T1DM diagnosis 
in a city in northern Italy. The mean age of the mothers was 44.20 , and the mean age of their children was 11.48 years. We chose to focus on parents of school-age children because, as described above, up to this age, diabetic children rely more on their families than they do in subsequent years.

\section{MEASUREMENTS}

Socio-demographic information. Respondents were asked to provide socio-demographic data such as parent's age, education level, employment status, marital status, number of children, and child's characteristics (i.e., age and age at the time of diagnosis).

The Fear of Hypoglycemia Survey-Parent Version (HFSP) ${ }^{17,45}$ was used to measure the concern experienced associated with hypoglycemia in parents of children and adolescents with T1DM.

The instrument was translated into Italian by Jesse Grabman's research group at the University of Virginia Behavioral Medicine Center using the translation process recommended by the World Health Organization. The HFS-P has been adapted from the original HFS-Adult version and is a 25 -item survey that includes a 15 -item worry subscale (helplessness/worry about low blood glucose, worry about negative social consequences) and a 10-item behavior subscale (maintaining high blood glucose, avoiding/preventing low blood glucose). Worry subscale items assess the anxiety and preoccupation that parents can experience due to low blood glucose levels in their children and the possible negative social consequences (e.g., Children not recognizing/realizing that they are experiencing a low blood glucose level). The behavior subscale items measure specific. Inappropriate behaviors are used to maintain high blood glucose levels and avoid hypoglycemia (e.g., Keep my child's blood sugar higher when they plan to be away from me for a while).

The items are rated on a five-point Likert scale ranging from 1 (never) to 5 (always). Higher scores indicate a higher fear of hypoglycemia. Cronbach's alpha showed good internal consistency for the worry subscale (.88) and the behavior subscale (.62). Some information related to the child's T1DM (i.e., the most recent HbA1c value) and the experience of severe hypoglycemic episodes were also included.

The Resilience Scale for Adults (RSA) was used to measure resilience among adults. This study employs the Italian version, ${ }^{46}$ which was carried out following the guidelines recommended by the World Health Organization.

The RSA is a 33-item self-report scale divided into $6 \mathrm{sub}$ scales: perception of self (PS - 6 items, e.g., When something unforeseen happens, I always find a solution), planned future (PF - 4 items; e.g., My goals for the future are well thought though), structured style (SS - 4 items, e.g., I am good at organizing my time), social competence (SC - 6 items; e.g., I enjoy being together with other people), family cohesion (FC - 6 items; e.g., My family is honest with each other), and social resources (SR - 7 items; e.g., I can discuss personal issues with friends/family members). The subscales consider psychological characteristics, family support, and social resources that lay the foundation of resilience. The items are rated on a 5-point semantic differential response format. The scores are calculated considering the reverse items.
Higher scores indicate higher levels of protective resources associated with resilience.

The Resilience Scale for Adults has been shown to have satisfactory psychometric qualities. The Cronbach's alpha coefficients for the subscales in the study were .67 (perception of self), .74 (planned future), .43 (structured style), .68 (social competence), .76 (family cohesion), and .81 (social resources).

The Self-Perception of the Parental Role (SPPR) evaluated parents' feelings about different aspects of the parenting role. The current study employs the Italian version. ${ }^{24}$

The SPPR contains 22 items represented by four subscales: competence ( 6 items), satisfaction (5 items), investment (5 items), and role balance (6 items). Each item presents a pair of conflicting statements that describe two endpoints of a dimension to minimize socially desirable responses, for example, "Some mothers and some fathers are not sure they were suited to be parents," but "Parenting comes easily and naturally to other parents". The participants choose the statement that best describes them and then decide upon the option of "true enough for me" or "absolutely true for me" based on their agreement. The four response choices are weighted as 1, 2, 3, and 4. The scores are calculated considering the reverse items. Higher scores indicate positive levels of parental self-perception. The SPPR subscales have demonstrated internal reliability. ${ }^{24,47,48}$ The Cronbach's alpha coefficients of the subscales in the study were .47 (competence), .43 (satisfaction), .32 (investment), and .65 (role balance).

\section{STATISTICAL ANALYSES}

Data analysis was performed using the SPSS statistical package, version 22, for Windows (IBM SPSS Statistics for Windows, version 22.0., 2014, IBM Corp) and the PROCESS macro program by Hayes (2012, model 7).

Preliminary analyses were carried out to compute the descriptive statistics. We proceeded to test the general patterns of association between the study variables (fear of hypoglycemia, resilience, and parental role) using Pearson's correlation coefficients.

Using the PROCESS tool, we conducted two mediation analyses to examine the direct effect of parental competence and role balance on the fear of hypoglycemia and the indirect effect of resilience on the relationship between parental role and fear of hypoglycemia. We used regression to assess the impact of some variables (age of a child, parental competence) on the fear of hypoglycemia. A pvalue of $<.05$ was considered significant.

ETHICS

The data collection procedure fully complied with the Research Ethical Code of the Italian Association of Psychology and the ethical recommendations of the Declaration of Helsinki and the American Psychological Association (APA) standards for the treatment of human volunteers.

Data will be treated in compliance with the privacy law (Legislative Decree No. 196/2003). 
Table 1. Descriptive statistics of participants and study variables

\begin{tabular}{|c|c|c|c|c|c|}
\hline & Min & Max & Mean & s.d. & $\mathrm{N}(\%)$ \\
\hline Mother age (years) & & & 44,20 & 6.11 & \\
\hline Child age (years) & & & 11,48 & 4.79 & \\
\hline Time since diagnosis (years) & & & 4,26 & .60 & \\
\hline Marital status (married) & & & & & $68(75,4)$ \\
\hline Qualification (high school diploma) & & & & & $50(55,3)$ \\
\hline Occupation (employee) & & & & & $59(65,9)$ \\
\hline Parental Investment (SPPR) & 1 & 4 & 2,58 & ,46 & \\
\hline Parental Competence (SPPR) & 1 & 4 & 2,66 &, 54 & \\
\hline Role Balance (SPPR) & 1 & 4 & 3,02 &, 53 & \\
\hline Parental Satisfaction (SPPR) & 1 & 4 & 2,72 & ,35 & \\
\hline Worry (HFS-P) & 1 & 5 & ,94 & ,67 & \\
\hline Behavior (HFS-P) & 1 & 5 & 1,96 &, 55 & \\
\hline Resilience & 1 & 5 & 3,71 &, 58 & \\
\hline
\end{tabular}

\section{RESULTS}

The descriptive statistics about the participants and study variables are presented in Table 1.

At the time of compilation, an average of 4.26 years had passed since diagnosis. Most of the mothers were married (75.4\%), held a high school diploma (55.3\%), and were employed (65.9\%).

Regarding the perception of the parental role, the participants reported values that were significantly lower than the normative values ${ }^{24}$ in all subscales: investment $(t=12.29, p>.000)$, competence $(t=25.82 ; t<.000)$, role balance $(\mathrm{t}=26.00 ; \mathrm{p}<.000)$ and satisfaction $(\mathrm{t}=58.78 ; \mathrm{p}<.000)$. This could indicate a generally negative perception of their parental role.

However, the mothers reported a lower fear of hypoglycemia than did the normative sample both for the worry subscale $(\mathrm{t}=16.41 ; \mathrm{p}<.000)$ and the behavior subscale $(\mathrm{t}=8.5$; $\mathrm{p}<.000)$.

The average score on the resilience scale was also significantly lower $(\mathrm{t}=2.09 ; \mathrm{p}<.03)$ than that of the comparison group. ${ }^{49}$

Correlations among the main variables of the study underlined a positive association between resilience and parental competence $(\mathrm{r}=.37 ; \mathrm{p}<.01)$, resilience and role balance $(\mathrm{r}=.38 ; \mathrm{p}<.01)$, and resilience and parental satisfaction $(\mathrm{r}=.24 ; \mathrm{p}<.01)$, while there was a negative association between resilience and worry about hypoglycemia $(r=-.29$; $\mathrm{p}<.01)$ and resilience and negative behaviors to prevent hypoglycemia $(\mathrm{r}=-.22 ; \mathrm{p}<.01)$. Parental investment is positively correlated with the behavior subscale (HFS-P) $(r=.28$; $\mathrm{p}<.01)$.

\section{MEDIATION MODEL}

The analysis of the mediation model allowed us to underline two models in particular, as described below.

In the first mediation model, competence in the parental role was inserted as an independent variable, the resilience of the mother was used as the mediator, and the worry

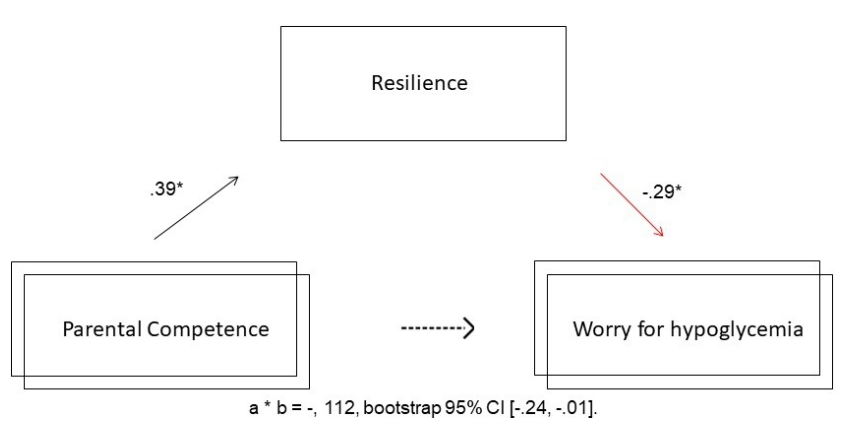

Figure 1

about possible hypoglycemia for the child was used as the dependent variable; the control variable taken into account was the number of hypoglycemic episodes reported by mothers in the last six months.

The conceptual map is shown in figure 1.

As hypothesized, perceived competence in the parent role positively influenced parents' resilience level $(b=.39$, $\mathrm{SE}=0.11, \mathrm{t}(2.87)=3.62, \mathrm{p}=.0005)$, regardless of the number of hypoglycemic episodes $(\mathrm{p}=.75)$.

In contrast, the parents' resilience level was negatively associated with worry about the possible hypoglycemia of the child, $\mathrm{b}=-.29, \mathrm{SE}=.13, \mathrm{t}(3.86)=-2.28, \mathrm{p}=.02$, regardless of the number of hypoglycemic episodes $(p=.28)$.

In support of our hypothesis of mediation, the level of resilience mediated the relationship between the perceived competence in the parental role and the worry about the possible hypoglycemia of the child, and the indirect effect of satisfaction on such worry was significant; $a * b=-, 112$, bootstrap 95\% CI [-.24, -.01].

In other words, the mediation model confirmed how mothers' competence in their parenting role can increase their resilience level and that the latter can influence the mothers' worry about the possible hypoglycemic status of their child.

In the second proposed mediation model, the independent variable was modified by the insertion of role balance 
related to the parental role, while the level of parent resilience and worry about the possible hypoglycemia of the child were again introduced as the mediator and dependent variables, respectively; the considered control variable was the number of hypoglycemic episodes reported by parents in the last six months.

The conceptual framework is shown in figure 2.

As expected, the perceived role balance with respect to the parental role was positively correlated with the parent's resilience level $\mathrm{b}=.41, \mathrm{SE}=.11, \mathrm{t}(2.87)=3,85, \mathrm{p}=.0002$, regardless of the number of hypoglycemic episodes $(\mathrm{p}=.48)$. Conversely, the resilience level of parents was negatively associated with worry about the possible hypoglycemia of the child, $\mathrm{b}=-.32, \mathrm{SE}=.13, \mathrm{t}(3.86)=-2,52, \mathrm{p}=.01$, regardless of the number of hypoglycemic episodes $(p=.26)$.

As a confirmation of our assumption, according to which the level of resilience mediates the relationship between the perceived role balance and worry about the possible hypoglycemia of the child, the indirect effect of role balance on the worry was significant; $a * b=-.134$, Bootstrap 95\% CI [-0.2691, -0.0216].

In short, it can therefore be affirmed that the perceived role balance of the mother concerning her parenting role can influence the development and increase of the mother's resilience, which in turn can decrease the mother's worry about the possible hypoglycemic episode of her child.

In conclusion, the relationships between competence and worry or role balance and worry can be defined as the indirect effect mediated by the mother's resilience level variable.

\section{DISCUSSION}

Given the importance of family caregiving in chronic disease, this study aimed to explore how the mothers of children with T1DM perceive their parenting role and, second, whether resilience mediates the relationship between effective self-perception and fear of hypoglycemia.

The results underline that mothers who perceive themselves as having a greater level of competence and role balance develop a greater level of resilience, which, in turn, mediates the relationship and allows a decrease in the level of preoccupation towards possible hypoglycemic episodes of the child.

According to a recent study, ${ }^{1}$ parents' perceptions are relevant variables related to guiding and modulating parenting emotions in interactions with their children. The latest research suggests that if parents feel more competent, they are more effective at managing their feelings and behaviors to support their children. ${ }^{50}$

The mediation role of resilience represents the most relevant result of our study because this element could contribute to reducing one's fear of hypoglycemia, and the literature has demonstrated that this reduction has a positive effect on adherence and thus the management of childhood diabetes. ${ }^{51,52}$ Parental competence and role balance could be considered protective factors, i.e., characteristics of a person or environment, increasing resilience, and modifying parents' response to stressors.

One aspect of the results to highlight is that resilience seems to act as a mediator concerning fear but not con-

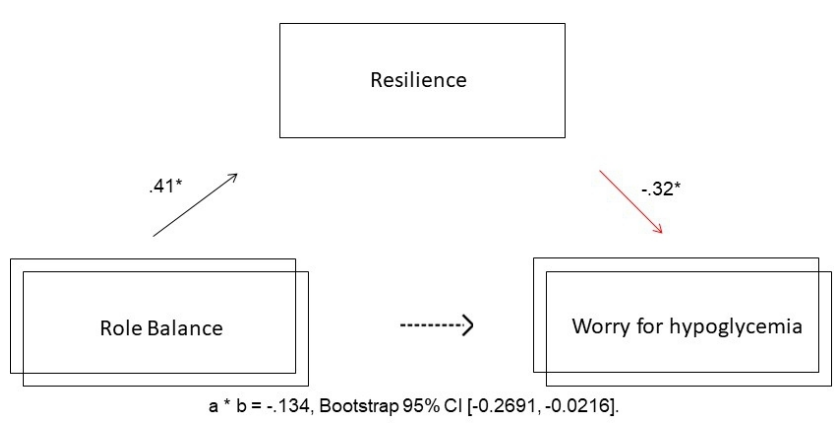

Figure 2

cerning maladaptive behavior, which could be related to the fact that other variables, such as the coping strategies of subjects, could intervene in the relationship. Furthermore, resilience may be related to the ability to think and recognize resources and successes. Regarding this aspect, the literature suggests that sharing experiences and narratives through reflection may strengthen resilience. ${ }^{32}$ Mothers with higher levels of resilience may be most protected from the adverse effects of worry about hypoglycemia in their children.

The literature underlines how parents with an increased ability to be less judgmental of themselves as parents report less fear of hypoglycemia ${ }^{53}$; this finding appears coherent with the outcomes of our study because mothers who perceive themselves as having higher levels of competence and role balance could be those who have a better awareness of themselves as good parents.

The possibility of perceiving a good role balance refers to the idea of integrating parenthood into one's life. For these women, the parenting role does not represent the only identifying element of their personality; however, according to social identity theory, ${ }^{54}$ we can speak of selfcomplexity. ${ }^{55,56}$ This element is associated in the literature with higher levels of wellbeing since it has a protective function for the person's self-esteem. ${ }^{57,58}$ In our case, it also seems to be a predictive element in the development of resilience, which has been measured considering individual and social elements. Promoting parents' positive capabilities fosters resilience, allowing parents to view themselves as active agents in their role as parents.

The interest in studying the parental role concerns the importance of parents' role in the care, growth of their child, and the balance of their family, particularly in the case of chronic disease. ${ }^{59}$ The literature has recently focused on emotions, routines, and educational processes that arise after T1DM onset and that definitively change family life. ${ }^{6}$

The need to adopt a family-centered approach to children's chronic conditions has been repeatedly emphasized. ${ }^{60,61}$

The extreme complexity of parents' management of family life has been underlined and conditioned both from a practical and psychological point of view. The parental role is consumed by responsibilities and concerns related to therapy management. ${ }^{62}$ In particular, in our study, the focus was on the relationships between the variables of fear about hypoglycemia, the self-perception of the parental 
role, and resilience; the current study represents one of the first empirical examinations of how parents are affected by having a child with T1DM that focuses explicitly on resilience as a mediating factor. Resilience could be considered a process that increases due to the self-perception of parents and that modifies the parents' response to chronic circumstances.

The present study identifies some important variables (i.e., parents' perception of their parental role) that can be used to develop more accurate future interventions in clinical practice for parents. However, there are some limitations of the study that should be noted. First, the findings are based on a convenience sample, and thus, the results cannot be generalized. Second, only mothers were recruited, and further research is needed to explore whether similar patterns of results are present for fathers. Although our sample size was sufficient for this exploratory study, a more extensive and more diverse sample would be more informative. It could also ensure the inclusion of a more representative range of people. Future studies should incorporate other viewpoints and other influencing factors to enrich the framework and provide a deeper understanding of the relationship between parental role perception and fear of hypoglycemia. Furthermore, future research may apply a mixed-method to deepen how the resilience process acts and if specific dimensions of resilience might impact mothers' anxiety.

Despite the limitations described above, the present study can be read as a preliminary work that has yielded useful results for future research. The findings suggest that parents with high levels of resilience may show lower levels of fear towards their child developing hypoglycemia.

The findings of the current study have important implications for clinical practice. Mothers who are at risk for experiencing difficulties regarding parenting a young child with T1DM could be targeted to participate in interventions to reduce their levels of worry through resilience improvement. The fundamental role of resilience as a mediator between the perception of individuals as parents and their fear of hypoglycemia makes it evident that the implementation of projects aimed at fostering parents' perception of their role within services is essential and useful; thus, professionals, after adequate preparation, can promote individual and family skills to help parents overcome adversity.

To conclude, it is important to highlight the fundamental processes underlying resilience, such as social support, to transfer the knowledge obtained from research to intervention.

Submitted: May 09, 2021 EST, Accepted: August 06, 2021 EST 


\section{REFERENCES}

1. Di Riso D, Bassi G, Mancinelli E, Zaffani S, Salcuni $\mathrm{S}$, Maffeis C. Mothers and fathers parenting stress and their perception of children's psychosocial functioning in paediatric diabetes: A pilot study. IJERPH. 2020;17(13):4734. doi:10.3390/ijerph1713473 $\underline{4}$

2. Pate T, Klemenčič S, Battelino T, Bratina N. Fear of hypoglycemia, anxiety, and subjective well-being in parents of children and adolescents with type 1 diabetes. Journal of Health Psychology. 2016;24(2):209-218. doi:10.1177/1359105316650931

3. Lawton J, Waugh N, Barnard KD, et al. Challenges of optimizing glycaemic control in children with Type 1 diabetes: A qualitative study of parents' experiences and views. Diabet Med. 2014;32(8):1063-1070. doi:1 $\underline{0.1111 / \text { dme. } 12660}$

4. Bianchi C, Rossi E, Miccoli R. Epidemiologia del diabete. In: Bonora E, Sesti G, eds. Il Diabetes in Italia. Bononia University Press; 2016:13-20.

5. Goldberg A. Sense of Coherence and Resolution with Diagnosis among Parents of Adolescents with Type 1 Diabetes. Journal of Pediatric Nursing. 2015;30(6):862-867. doi:10.1016/j.pedn.2015.06.004

6. Fornasini S, Miele F, Piras EM. The Consequences of Type 1 Diabetes Onset On Family Life. An Integrative Review. Journal of Child and Family Studies. 2020;29(5):1467-1483. doi:10.1007/s10826-01 9-01544-Z

7. Messina R, Due-Christensen M, Keller-Senn A, Polek E, Fantini MP, Sturt J. Couples living with type 1 diabetes: An integrative review of the impacts on health and wellbeing. J Health Psychol. 2018;26(3):412-437. doi:10.1177/1359105318817356

8. Landers SE, Friedrich EA, Jawad AF, Miller VA. Examining the interaction of parental involvement and parenting style in predicting adherence in youth with type 1 diabetes. Families, Systems, \& Health. 2016;34(1):41-50. doi:10.1037/fsh0000183

9. Mackey ER, Herbert L, Monaghan M, Cogen F, Wang J, Streisand R. The feasibility of a pilot intervention for parents of young children newly diagnosed with type 1 diabetes. Clinical Practice in Pediatric Psychology. 2016;4(1):35-50. doi:10.1037/cpp $\underline{0000123}$
10. Yi-frazier JP, Yaptangco M, Semana S, et al. The association of personal resilience with stress, coping, and diabetes outcomes in adolescents with type 1 diabetes: Variable- and person-focused approaches. $J$ Health Psychol. 2015;20(9):1196-1206. doi:10.1177/13 $\underline{59105313509846}$

11. Morgan-Trimmer S, Channon S, Gregory JW, Townson J, Lowes L. Family preferences for home or hospital care at diagnosis for children with diabetes in the DECIDE study. Diabetic Medicine. 2015;33:119-124. https://doi.org/

12. Patton SR, Dolan LM, Smith LB, Thomas IH, Powers SW. Pediatric Parenting Stress and Its Relation to Depressive Symptoms and Fear of Hypoglycemia in Parents of Young Children with Type 1 Diabetes Mellitus. J Clin Psychol Med Setting. 2011;18:345-352. https://doi.org/

13. Kobos E, Imiela J. Factors affecting the level of burden of caregivers of children with type 1 diabetes. Applied Nursing Research. 2015;28(2):142-149. doi:1 0.1016/j.apnr.2014.09.008

14. Ly TT, Maahs DM, Rewers A, Dunger D, Oduwole A, Jones TW. Assessment and management of hypoglycemia in children and adolescents with diabetes. Pediatr Diabetes. 2014;15(S20):180-192. do i:10.1111/pedi.12174

15. Patton SR, Dolan LM, Henry R, Powers SW. Parental fear of hypoglycemia: Young children treated with continuous subcutaneous insulin infusion. Pediatr Diabetes. 2007;8(6):362-368. doi:10.1111/j.139 9-5448.2007.00242.x

16. Patton SR, Dolan LM, Henry R, Powers SW. Fear of Hypoglycemia in Parents of Young Children with Type 1 Diabetes Mellitus. J Clin Psychol Med Setting. 2008;15(3):252-259. https://doi.org/

17. Haugstvedt A, Wentzel-Larsen T, Aarflot M, Rokne $\mathrm{B}$, Graue M. Assessing fear of hypoglycemia in a population-based study among parents of children with type 1 diabetes - psychometric properties of the hypoglycemia fear survey - parent version. $B M C$ Endocr Disord. 2015;15(1). doi:10.1186/1472-6823-1 $\underline{5-2}$

18. Emiliani F, Melotti G, Palareti L. Routine e rituali della vita familiare quali indicatori di rischio psicosociale. Psicologia clinica dello sviluppo. 1998;3,(3):421-448. doi:10.1449/536

19. Fiese BH. Family Routines and Rituals. Yale University Press; 2006. 
20. Migliorini L, Rania N, Cardinali P. The scaffolding function of family routine and rituals during children preschool age. Psicologia Clinica dello Sviluppo. 2015;19, 1:155-164.

21. Viaene AS, Van Daele T, Bleys D, Faust K, Massa GG. Fear of Hypoglycemia, Parenting Stress, and Metabolic Control for Children with Type 1 Diabetes and Their Parents. J Clin Psychol Med Settings. 2017;24(1):74-81. doi:10.1007/s10880-017-9489-8

22. Frantzen KK, Lauritsen MB, Jørgensen M, et al. Parental Self-perception in the Autism Spectrum Disorder Literature. a Systematic Mixed Studies Review, Rev J Autism Dev Disord. 2016;3:18-36.

23. Patton SR, Clements MA, George K, Goggin K. "I Don't Want Them to Feel Different”: A Mixed Methods Study of Parents' Beliefs and Dietary Management Strategies for Their Young Children with Type 1 Diabetes Mellitus. Journal of the Academy of Nutrition and Dietetics. 2016;116(2):272-282. doi:1 0.1016/j.jand.2015.06.377

24. Del Vecchio E, Di Riso D, Salcuni S. SelfPerception of Parental Role, Family Functioning, and Familistic Beliefs in Italian Parents: Early Evidence. Front Psychol. 2016;6:1-9. doi:10.3389/fpsyg.2015.019 $\underline{83}$

25. Laquale MG, Coppola G, Cassibba R, et al. Confidence in Attachment Relationships and Marital Status as Protective Factors for Self-Perceived Parental Role and In-Person Visitation with Children Among Incarcerated Fathers. J Forensic Sci. 2018;63(6):1761-1768. doi:10.1111/1556-4029.13793

26. Bishop J, Roberson PN, Norona JC, Welsh DP. Does Role Balance Influence the Effect of Personality on College Success? A Mediation Model. Emerging Adulthood. 6:137-148.

27. Migliorini L, De Piccoli N. Challenging gender perspective in the community to promote well-being and health. J Prev Interv Community.

2019;48(2):121-131. doi:10.1080/10852352.2019.1624 $\underline{352}$

28. Haugstvedt A, Wentzel-Larsen T, Graue M, Søvik $\mathrm{O}$, Rokne B. Fear of hypoglycaemia in mothers and fathers of children with Type 1 diabetes is associated with poor glycaemic control and parental emotional distress: A population-based study. Diabetic Medicine. 2010;27(1):72-78. doi:10.1111/j.1464-5491.2009.0286 7.X

29. Cardinali P, Migliorini L, Rania N. The caregiving experiences of fathers and mothers of children with rare diseases in Italy: Challenges and social support perceptions. Front Psychol. 2019;10(JULY):1780. doi:1 $\underline{0.3389 / \text { fpsyg. } 2019.01780}$
30. Hannonen R, Aunola K, Eklund K, Ahonen T. Maternal Parenting Styles and Glycemic Control in Children with Type 1 Diabetes. Int J Environ Res Public Health. 2019;16(2):214. doi:10.3390/ijerph16020214

31. Schwarzer R, Warner LM. Perceived self-efficacy and its relationship to resilience. In: Prince-Embury S, Saklofske DH, eds. The Springer Series on Human Exceptionality: Resilience in Children, Adolescents, and Adults: Translating Research into Practice. ; 2013:139-150. https://www.researchgate.net/deref/ht tp\%3A\%2F\%2Fdx.doi.org\%2F10.1007\%2F978-1-461 4-4939-3 10

32. Kralik D, van Loon A, Visentin K. Resilience in the chronic illness experience. Educational Action Research. 2006;14(2):187-201. doi:10.1080/096507906 $\underline{00718035}$

33. Sagone E, Caroli M. Relationships between Resilience, Self-Efficacy, and Thinking Styles in Italian Middle Adolescents. Procedia - Social and Behavioral Sciences. 2013;92:838-845. doi:10.1016/i.sb spro.2013.08.763

34. Mullins LL, Molzon ES, Suorsa KI, Tackett AP, Pai ALH, Chaney JM. Models of Resilience: Developing Psychosocial Interventions for Parents of Children with Chronic Health Conditions. Interdisciplinary Journal of Applied Family Studies. 2015;64(1):176-189. doi:10.1111/fare.12104

35. Masten AS, Obradovic J. Competence and resilience in development. Annals of the New York Academy of Sciences. 2006;1094(1):13-27. doi:10.1196/ annals.1376.003

36. Dong X, Li G, Liu C, et al. The mediating role of resilience in the relationship between social support and posttraumatic growth among colorectal cancer survivors with permanent intestinal ostomies: A structural equation model analysis. European Journal of Oncology Nursing. 2017;29:47-52. doi:10.1016/i.ejo $\underline{\text { n.2017.04.007 }}$

37. Min JA, Yoon S, Lee CU, et al. Psychological resilience contributes to low emotional distress in cancer patients. Support Care Cancer. 2013;21(9):2469-2476. doi:10.1007/s00520-013-180 $\underline{7-6}$

38. Shin JI, Chae JH, Min JA, et al. Resilience as a possible predictor for psychological distress in chronic spinal cord injured patients living in the community. Annals of rehabilitation medicine. 2012;36(6):815-820. doi:10.5535/arm.2012.36.6.815S $\underline{\text { mith }}$ 
39. Kentor RA, Hilliard ME. JPP Student Journal Club Commentary: Considerations on Depression, Distress, and Resilience in Parents of Children With Chronic Health Conditions. Journal of Pediatric Psychology. 2019;44, 2:150-152,. doi:10.1093/jpepsy/i sy096Kobos

40. Lee I, Lee EO, Kim HS, Park YS, Song M, Park YH. Concept development of family resilience: A study of Korean families with a chronically ill child. J Clin Nurs. 2004;13(5):636-645. doi:10.1111/i.1365-2702.20 04.00845.X

41. Walsh F. Family resilience: A developmental systems framework. European Journal of

Developmental Psychology. 2016;13(3):3131-3324. do i:10.1080/17405629.2016.1154035

42. Smith AM, Grzywacz JG. Health and Well-Being in Midlife Parents of Children With Special Health Needs. 2014;32(3):303-312. https://doi.org/

43. Mednick L, Cogen F, Henderson C, Rohrbeck CA, Kitessa D, Streisand R. Hope more, worry less: Hope as a potential resilience factor in mothers of very young children with Type 1 diabetes. Children's Health Care. 2007;36(4):385-396. doi:10.1080/027396 10701601403

44. Yi JP, Vitaliano PP, Smith RE, Yi JC, Weinger K. The role of resilience on psychological adjustment and physical health in patients with diabetes. British Journal of Health Psychology. 2008;13(2):311-325. 으 i:10.1348/135910707x186994

45. Gonder-Frederick L, Nyer M, Shepard JA, Vajda K, Clarke W. Assessing fear of hypoglycemia in children with type 1 diabetes and their parents. Diabetes Management. 2011;1(6):627-639. doi:10.2217/dmt.1 1.60

46. Bonfiglio NS, Renati R, Hjemdal O, Friborg O. The Resilience Scale for Adults in Italy: A Validation Study Comparing Clinical Substance Abusers With a Nonclinical Sample. Psychology of Addictive Behaviors. 2016;30(4):509-515. doi:10.1037/adb0000176

47. MacPhee D, Benson JB, Bullock D. Influences on maternal self-perceptions. Infant Behavior and Development. 1986;9(236):236. doi:10.1016/s0163-638 3(86)80239-9

48. Bornstein MH, Hendricks C, Hahn CS, Haynes OM, Painter KM, Tamis-LeMonda CS. Contributors to selfperceived competence, satisfaction, investment, and role balance in maternal parenting: A multivariate ecological analysis. Parent Sci Pract. 2003;3(4):285-326. doi:10.1207/s15327922par0304_2

49. Peveri L. Resilienza e regolazione delle emozioni. Un approccio multimodale. Published online 2009.
50. Ziv I, Golbez N, Shapira N. Parental sense of competence, resilience, and empathy in relation fathers' responses to children's negative emotions in the context of everyday paternal childrearing decisions. Cogent Psychology. 2020;7, 1:1794681. doi:1 $0.1080 / 223311908.2020 .1794681$

51. Freckleton E, Sharpe L, Mullan B. The relationship between maternal fear of hypoglycaemia and adherence in children with type-1 diabetes. Int Behav Med. 2014;21(5):804-810. doi:10.1007/s12529-013-93 $\underline{60-8}$

52. Wild D, von Maltzahn R, Brohan E, Christensen T, Clauson P, Gonder-Frederick L. A critical review of the literature on fear of hypoglycemia in diabetes: Implications for diabetes management and patient education. Patient Education and Counseling. 2007;68(1):10-15. doi:10.1016/j.pec.2007.05.003

53. Aalders J, Hartman E, Nefs G, et al. Mindfulness and fear of hypoglycaemia in parents of children with Type 1 diabetes: Results from Diabetes MILES Youth The Netherlands. Diabet Med. 2018;35(5):650-657. do $\mathrm{i}: 10.1111 /$ dme.13594

54. Tajfel H, Turner JC. An integrative theory of intergroup conflict. In: Austin WG, Worchel S, eds. The Social Psychology of Inter-Group Relations. Brooks/ Cole; 1979:33-47.

55. Kalthoff RA, Neimeyer RA. Self-complexity and psychological distress: A test of the buffering model. International Journal of Personal Construct Psychology. 1993;6(4):327-349. doi:10.1080/08936039308405628

56. Koch EJ, Shepperd JA. Is self-complexity linked to better coping? A review of the literature. J Personality. 2004;72(4):727-760. doi:10.1111/j.0022-3506.2004.00 278.x

57. Linville PW. Self-complexity as a cognitive buffer against stress-related illness and depression. Journal of Personality and Social Psychology. 1987;52(4):663-676. doi:10.1037/0022-3514.52.4.663

58. Rafaeli-Mor E, Steinberg J. elf-complexity and wellbeing: A review and research synthesis. Personality and Social Psychology Review. 2002;6(1):31-58. doi:10.1207/s15327957pspr0601 2

59. Revenson TA, Griva K, Luszczynska A, Morrison V, Panagopoulu E, Vilchinsky N, et al. Caregiving in the Illness Context. Palgrave Macmillan; 2015.

60. American Academy of Pediatrics. Committee on Hospital Care. Family-Centered Care and the Pediatrician's Role. Pediatrics. 2003;112(3 Pt 1):691-696. doi:10.1542/peds.112.3.691 
61. Migliorini L, Rania N. La prevenzione primaria del disagio del minore: Il ruolo pivot dei pediatri di famiglia. Quaderni ACP. 2016;23:26-27.
62. Helgeson VS, Zajdel M. Adjusting to Chronic Health Conditions. Annu Rev Psychol. 2017;68(1):545-571. doi:10.1146/annurev-psych-0104 $\underline{16-044014}$ 